TUGAS ETIKA MORAL

\title{
ANALISIS KASUS YANG TERJADI DALAM KEHDUPAN SEHARI-HARI DI INDONESIA
}

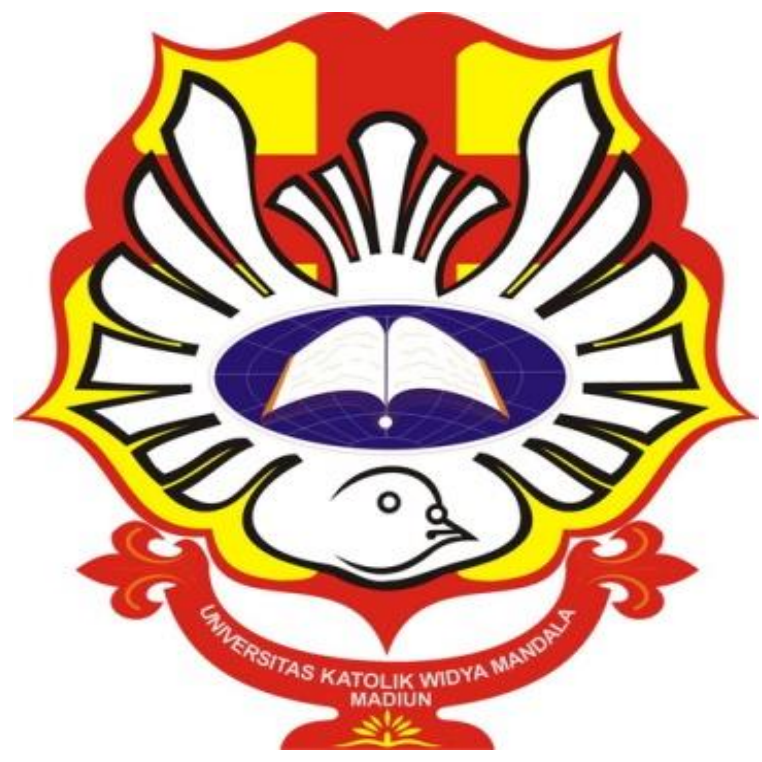

Disusun oleh:

Nama: Marselinus Hosea Astro

Nim: 12418005

\section{Program Pendidikan Bahasa dan Sastra Indonesia FKIP}

Universitas Widya Mandala Madiun 


\begin{abstract}
$\underline{\text { Abstrak }}$
Dalam kasus ini saya akan membahas tentang persoalan Etika. Kasus ini terjadi di Jakarta. seorang Ketua tim hukum Prabowo-Sandiaga Bambang Widjojanto diadukan ke perhimpunan Advokat Indonesia pimpinan fauzi Hasibuan di kantor peradilan, Jakarta Barat pada kamis (1306-2019) laporan ini dilakukan oleh sekumpulan Aadvokat yang tergabung dalam Advokat indonesia Maju melaporkan Bambang Widjojanto (BW). Bambang Widjojanto diadukan untuk dua persoalan Etika. Pertama, mantan pimpinan Komisi pemberantasan Korupsi (KPK) disebut melangar Etika saat menjadi kuasa hokum prabowo namun masih aktif sebagai pejabat Negara. Bambang Widjojanto diangap melangar Etika karena merendahkan MK tak hanya soal jabatannya sebagai ketua TGUPP, Bambang Widjojanto juga diadukakan untuk persoalan etika kedua kalinya ini terkait pernyataannya yang dinilai merendahkan Mahkamah konsitusi.

Kasus ini sangat jelas melangar Etika. Secara umum dapat dikatakan bahwa etika adalah filsafat tentang tindakan manusia. suatu tindakan itu mempunyai nilai etis bila dilakukan oleh manusia. sangatlah jelas bahwa etika itu berurusan secara langsung dengan tindakan atau tingkah laku manusia. Tingkah laku manusia ini bukan tingkah laku yang tidak ada artinya.
\end{abstract}




\section{A) Dilaporkan ke Peradi karena Persoalan Etika, Ini Kata Bambang}

$\underline{\text { Widjojanto }}$

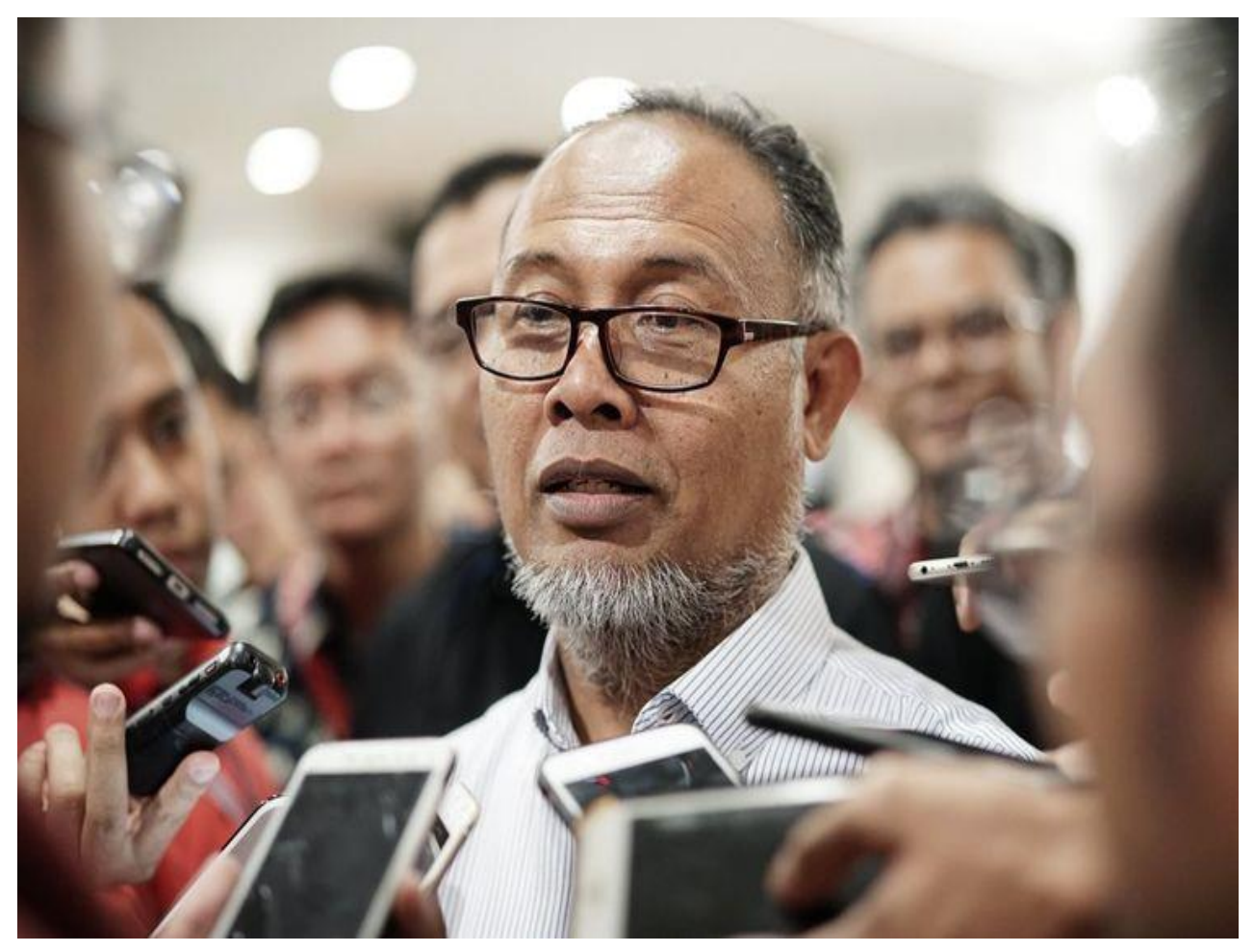

JAKARTA, KOMPAS.com - Ketua tim hukum Prabowo-Sandiaga, Bambang Widjojanto diadukan ke Perhimpunan Advokat Indonesia pimpinan Fauzi Hasibuan di Kantor Peradlani, Jakarta Barat pada Kamis (13/06/2019). Laporan dilakukan oleh sekumpulan advokat yang tergabung dalam Advokat Indonesia Maju melaporkan Bambang Widjojanto (BW).

BW diadukan untuk dua persoalan etika. Pertama, mantan pimpinan Komisi Pemberantasan Korupsi (KPK) itu disebut melanggar etika saat menjadi kuasa hukum Prabowo namun masih aktif sebagai pejabat negara. 
BW diketahu merupakan Ketua Bidang Pencegahan Korupsi, Tim Gubernur untuk Percepatan Pembangunan (TGUPP) di bawah Gubernur DKI Jakarta Anies Baswedan. Apa kata BW soal ini? "Tanya sama gubernurnya. Jangan bertindak seperti gubernur. Tanya gubernurnya dong," tukas dia saat tiba di gedung Mahkamah Konstitusi, Jumat (14/6/2019). Baca juga: Dilaporkan ke Peradi, Bambang Widjojanto Dianggap melanggar Etika dan mrendahkan MK Tak hanya soal jabatannya sebagai Ketua TGUPP, BW juga diadukan untuk persoalan etik kedua. Kali ini terkait pernyataannya yang dinilai merendahkan Mahkamah Konstitusi. Soal itu, BW pun bereaksi. "Saya sedang menjalankan tugas kenegaraan yang sangat berat dan mulia. Jadi hal-hal seperti itu saya persilakan karena fokus saya sekarang bagaimana memastikan bahwa rakyat itu betul-betul bisa didengar ya," ucap dia. Baca juga: Jadi Pengacara Prabowo, Bambang Widjojanto Cuti Sebulan dari TGUPP Seperti diketahui, selepas menyerahkan permohonan gugatan hasil Pilpres 2019 di Gedung MK pada Jumat 24 Mei 2019, Bambang Widjojanto meminta agar MK tak berubah menjadi 'Mahkamah Kalkulator'. Pernyataan ini yang dianggap Sandi merendahkan MK. Sandi berharap, BW segera dipanggil oleh Peradi.

\section{B. TEORI}

Etika adalah filsafat tentang tindakan-tindakan manusia sebagai manusia. Etika adalah filsafat yang berurusan dengan perbuatan atau tingkah laku manusia sejauh manusia.'Praxis' ialah tindakan Konkret yang langsung berkaitan dengan aktivitas kreatif, produktif, dan transformatif.'praxis' (Praksis) adalah tindakan yang bukan merupakan theoria (spekulatif). Praksis yang digumuli etika langsung berkaitan dengan tindakan manusia secara keseluruhan dari sudut pandang normaif. 
Secara umum dapat dikatakan bahwa etika adalah filsafat tentang tindakan manusia sebagai manusia. Suatu tindakan itu mempunyai nilai etis bila dilakukan oleh manusia dan dalam kerangka manusiawi. Jelas bahwa etika itu berurusan secara langsung dengan tindakan atau tingkah laku manusia. tingkah laku manusiawi ini bukan tingkah laku yang tidak ada artinya, tetapi yang mengajar nilai-nilai kebaikan.

Etika sebagai ilmu pengetahuan, dengan demikian, memiliki karakter normatif. Etika adalah ilmu pengetahuan normatif tentang tingkah laku manusia sejauh manusia secara keseluruhan. Sebagai yang memiliki karakter normatif, etika berkaitan langsung dengan norma-norma atau nilai-nilai atau prinsip-prinsip moral atau gagasan-gagasan etis kemanusiaan.

Disebut normatif, karena etika mengajukan nilai-nilai, atau polapola etis, menguji pertimbangan-pertimbangan moral dan aneka ragam perbuatannya dalam kehidupan manusia konkret dalam kehidupan seharihari. Etika menggalang aneka persoalan kehidupan, menguji, menganalisisnya, melucutinya dari soal-soal yang tidak manusiawikan kehidupan, dan menawarkan rupa- rupa pertimbangan etis moral yang tidak masuk akal.

\section{ACTUS HUMANIS: TAHU, MAU, BEBAS}

Actus humanis identik dengan free act (tindakan bebas). Dalam tindakan yang mengungkapkan kebebasan, manusia adalah subjek tindakan. Jadi, bilamana? Bila manusia yang bersangkutan adalah subjek terhadap perbuatannya. Ia lantas bertanggung jawab atas konsekuensi dari tindakan tersebut. Kebebasan mengandaikan dua hal, yaitu: tahu dan mau! 
Artinya, apa bila manusia itu mengetahui dan menghendaki, ia disebut manusia bebas, dan dengan demikian ia bertangung jawab atasnya. Kehilangan salah satu syarat ini, manusia tidak dapat berttangung jawab atas tindakannya.

'tahu' di sini maksudnya bukan hanya pengetahuan yang cukup terhadap objeknya atau sasaran perbuatannya, melainkankan juga mengenai dirinya sendiri. Misalnya: orang mabuk memperkosa seorang anak remaja, jelas tindakan tersebut melangar Etika.seorang tersebut bias mengenali dengan baik siapa dirinya dan siapa objeknya tindakannya.

'Mau'juga adalah syarat esensial kebebasan. Kebebasan berarti tidak ada Depannya. Misalnya: seorang tentara yang terikat kewajibannya menjalankan tugas masih dapat disebut memiliki kebebasan? Dalam keadaan normal memang ia terikat, meskipun sebenarnya ia masih memiliki kebebasan (desersi/keluar dari tentara misalnya).

\section{HATI NURANI}

Darimana kita mengenal hati nurani? Secara fenomenologis, dari realitas bahwa selalu melakukan pertimbangan-pertimbangan dalam hidupnya. Melakukan pertimbangan artinya manusia memiliki semacam tradisi nilai-nilai yang menjadi fedoman untuk menegaskan pilihan-pilihan dan melakukan keputusan.

Hati nurani pertama-tama menyentuh pengetahuan (atau kesadaran). Pengetahuan apa? Pengetahuan dari hati. Hati nurani berarti hati manusia memiliki pengetahuan. Hati nurani ialah hati yang mengetahui. Sebenarnya proposisi "hati yang mengetahui" sama sekali tidak tepat. Soal pengetahuan tak pernah merupakan soal hati, melainkan 
soal akal budi (rasio). Dan sebab itu, jika jika dikatakan hati nurani mengetahui, maksudnya ialah hati kita memiliki semacam pertimbangan yang membimbing kehendak kita.

Hati nurani disebut juga 'sinderasis'.Dalam bahasa inggris disebut "conscience" yang berkaitan langsung dengan kesadaran. Hati nurani menjadi seperti kapasitas/daya/ kekuatan yang pertimbangan dan pemeriksaannya mengatasi hukum, fendomen baik/buruk sebagaimana digagas oleh public kebanyakannya, mengatasi larangan atau perintah dalam peraturan-peraturan yang dimiliki dalam hidup manusia. Hati nurani dalam bagigan pengertian ini lantas di paham gaiseba suatu kesadaran batin/interior yang ada dalam problem kehidupan bersifat sekaligus atau serentak atau menyeluruh.

\section{E. KESIMPULAN}

Kesimpulan dari kasus diatas adalah bahwa kasus diatas sangatlah jelas-jelas melanggar etika. Bambang Widjojanto melanggar Etika dan tidak sesuai dengan nilai-nilai yang terkandung di dalam etika. Kasus Bambang Widjojanto di angap melangar Etika karena telah merendahkan MK. Tak hanya soal jabatannya sebagai ketua TGUPP, Bambang Widjojanto juga diadukakan untuk persoalan etika kedua kalinya ini terkait pernyataannya yang dinilai merendahkan Mahkamah konsitusi.

Secara umum dapat dikatakan bahwa etika adalah filsafat tentang tindakan manusia. suatu tindakan itu mempunyai nilai etis bila dilakukan oleh manusia. sangatlah jelas bahwa etika itu berurusan secara langsung dengan tindakan atau tingkah laku manusia. 


\section{Daftar pustaka}

Dewantara, A. (2017). Diskursus Filsafat Pancasila Dewasa Ini.

Dewantara, A. (2017). Filsafat Moral (Pergumulan Etis Keseharian Hidup Manusia).

Dewantara, A. W. (2015). Filosofi Pendidikan yang Integral dan Humanis dalam

Perspektif Mangunwijaya. JPAK: Jurnal Pendidikan Agama Katolik, 13(7), 3-9.

DEWANTARA, A. W. (2016). GOTONG-ROYONG MENURUT SOEKARNO

DALAM PERSPEKTIF AKSIOLOGI MAX SCHELER, DAN SUMBANGANNYA

BAGI NASIONALISME INDONESIA (Doctoral dissertation, Universitas Gadjah Mada). 